\title{
Cogging Torque Reduction in Permanent-Magnet Brushless Generators for Small Wind Turbines
}

\author{
Dae-Won Chung* and Yong-Min You \\ Department of Electrical Engineering, Honam University, Gwangiu, 507-714, Korea
}

(Received 5 February 2015, Received in final form 11 June 2015, Accepted 12 June 2015)

\begin{abstract}
We present the design optimization of the magnetic pole and slot design options that minimize the cogging torque of permanent-magnet (PM) brushless generators for small wind turbine generators. Most small windturbines use direct-driven PM generators which have the characteristics of low speed and high efficiency. Small wind-turbines are usually self-starting and require very simple controls. The cogging torque is an inherent characteristic of PM generators, and is mainly caused by the generator's geometry. The inherent the cogging torque can cause problems during turbine start-up and cut-in in order to start softly and to run a power generator even when there is little wind power during turbine start-up. Thus, to improve the operation of small turbines, it is important to minimize the cogging torque. To determine the effects of the cogging torque reductions, we adjust the slot opening width, slot skewing, mounting method of magnets, magnet shape, and the opening and combinations of different numbers of slots per pole. Of these different methods, we combine the methods and optimized the design variables for the most significant design options affecting the cogging torque. Finally, we apply to the target design model and compare FEA simulation and measured results to validate the design optimization.
\end{abstract}

Keywords : small wind turbine generator, permanent-magnet brushless generator, cogging torque reduction, finite element analysis (FEA)

\section{Introduction}

Recently, there has been increased interest in permanentmagnet (PM) generators for use with small wind turbines because they are compact, highly efficient, reliable, and self-excited. Power generation obtained from the wind primarily converts energy from the wind into mechanical energy through the rotating blades of a wind turbine, and the converted mechanical energy is used to drive a generator that produces electrical energy. Most small wind turbines use PM generators, which are usually direct-driven (i.e., no gearbox is required) rotors from the rotating blade. Direct-driven PM generators are characterized by simple controls, low-speed rotation, light weight, and high efficiency. The torque fluctuation in low-speed PM generators for small wind turbines causes noise, vibration and start-up problems. While the torque fluctuations may not be a serious issue at high speed, there may be major

CThe Korean Magnetics Society. All rights reserved.

*Corresponding author: Tel: +82-62-940-5494

Fax: +82-62-940-5053, e-mail: dwchung@honam.ac.kr problems at low speeds because of the above-mentioned issues. The main torque fluctuation components of PM generators are the torque ripples and the cogging torque; the PM torque ripple is the result of the interaction of the air-gap flux density high harmonics generated from the rotor magnets and the stator winding during normal operation. The cogging torque is produced by the shaft when the rotor of a PM generator is rotated with respect to the stator during no-load condition, i.e., the cogging torque is an inherent characteristic and is mainly caused by the geometry of the PM generators. The cogging torque affects the self-start ability, and produces noise and mechanical vibrations. Further, the inherent the cogging torque can cause problems that prevent it from starting softly and running a power generator, even when there is little wind power during turbine start-up $[3,4,8,13]$.

Previous works have shown that the electromagnetic properties of PM machines are highly dependent on the number of slots per pole per phase, as well as the shape of the magnets, the stator slots, and the slot opening. A large amount of PM material has to be used if the maximum air-gap flux density is higher than $0.8-0.85 \mathrm{~T}$ [5]. The 
ratio of the pull-out torque to the magnet weight is highest when the magnets pole's arc width is within the range $0.65-0.8 \mathrm{pu}$, with reference to the pole pitch [10]. The cogging torque can be minimized using several methods, including the fractional slots/pole winding, the suitable magnet pole-arc width, and the small slot-opening width.

In literatures, the cogging torque reduction methods that have been previously proposed to include:

- The use of a fractional number of slots per pole per phase $[1,13,14]$;

- The use of auxiliary slots or teeth [7];

- Magnet segmentation [6];

- The optimization of the sizes and pole-arc of magnets $[2,5,8,12]$

- The optimization of the magnet displacement and shaping [3-15]

- The skewing of stator slots or magnets $[1,2,11]$;

- Changing the width of the opening stator slot $[9,10]$, etc.

While each of these methods has its own advantage, they also have problems, e.g., the use of a fractional number of slots per pole reduces the amplitude of the cogging torque as is the case with the skewing of the magnets or the stator slots, results in increased difficulties associated with motor manufacturing. This reduction is achieved by increasing the number of torque cycles since each slot is located in a different angular position with respect to the magnets.

The main objective of this paper is to present design optimization of the magnetic pole and slot design options to minimize the cogging torque of a PM generator for small wind-turbine generators. We investigate and compared the methods to use the slot opening width, slot skewing, mounting method of magnets, magnet shape, and the opening and combinations of different numbers of slots per pole. Of these different methods, we optimized the design variables for the most significant design options affecting the cogging torque. Finally, we apply to the target design model and compare FEA simulation and measured results to validate the design optimization.

\section{Investigation of the Cogging Torque Reduction}

\subsection{Cogging Torque Theory}

The cogging torque is the oscillatory torque that results from the interaction between a PM's field and the stator slots, and it cause reluctance variations as the rotor position being expressed in change of the torque on the rotor during the interaction of the magnetic flux and the stator teeth, even when there is no stator current. The cogging torque occurs in PM generators in the air-gap between the rotor and the stator. As the rotor rotates, the change of the reluctance in the air-gap, which is due to the slots, results in the formation of the cogging torque. While the magnetic flux passes through the rotor to the stator, there are variations in the reluctance. The path of the magnetic flux begins from the magnets and the rotor, and it then follows the air-gap and stator; finally it returns via the same path. The reluctance of the air-gap is different from that of steel, which is used in the rotor and the stator. The flux plot and the cogging torque of PM machines are shown in Figs. 1 and 2, respectively. The cogging torque is given by:

$$
\tau_{c o g}=-\frac{1}{2} \phi_{g}^{2} \frac{d R}{d \alpha}
$$

where, $\phi_{g}, R$, and $\alpha$ are the air-gap flux, air-gap reluctance, and the angle position of the rotor, respectively [1]. This indicates that the cogging torque can be minimized by either making air-gap flux zero or by making the rate of change of the air-gap reluctance zero (i.e., $d R / d \alpha=0$ ). However, because the air-gap flux cannot be made zero, the cogging torque can be minimized by forcing the air-gap reluctance to be constant with respect to the rotor position. In practice, the cogging torque cannot be easily eliminated perfectly, but it can be significantly reduced [1].

The cogging torque can also be calculated by using the stored energy in the air gap as a force and the stored energy in the air-gap can be calculated using the virtual work. According to this definition, the cogging torque is given by:

$$
\tau_{\operatorname{cog}}=-\frac{\partial W_{c}}{\partial \alpha}
$$

where $W_{c}$, and $\alpha$ are the air-gap stored magnetic coenergy and the angle position of the rotor, respectively [2]. Even when there is no stator current, energy changes must happen only in the air-gap during rotor rotation. Therefore, we consider the energy changes only in the airgap [1] as given by:

$$
\begin{aligned}
W_{c}(\alpha) & =\frac{1}{2 \mu_{0}} \int|P(\theta) \cdot B(\theta, \alpha)|^{2} d V \\
& =\frac{1}{2 \mu_{0}} \int_{0}^{L_{s}} \int_{R_{i}}^{R_{o}} \int_{0}^{2 \pi}|P(\theta) \cdot B(\theta, \alpha)|^{2} d \theta r d r d z \\
& =\frac{1}{2 \mu_{0}} L_{s} \frac{1}{2}\left(R_{o}^{2}-R_{i}^{2}\right) \int_{0}^{2 \pi} P(\theta)^{2} B(\theta, \alpha)^{2} d \theta
\end{aligned}
$$


where $V, \theta, P(\theta), B(\theta, \alpha), L_{s}, R_{o}, R_{i}$ are the machine volume, the azimuthal angle around the stator bore, the permeance distribution, magnetic flux-density distribution, the stack length, and the outer radius and the inner radius of rotor, respectively. The permeance distribution and magnetic flux-density distribution in terms of Fourier series [1] can be expressed by:

$$
\begin{aligned}
& P(\theta)^{2}=\sum_{n=0}^{\infty} P_{n N_{s}} \cos n N_{s} \theta \\
& B(\theta, \alpha)^{2}=\sum_{n=0}^{\infty} B_{m N_{s}} \cos n N_{p}(\theta+\alpha)
\end{aligned}
$$

where $n, N_{s}, N_{p}$ are the $n^{\text {th }}$ harmonic, the number of slots and number of a pair poles, respectively. In these two equations, if we consider the orthogonal property of trigonometric function, then, the equation (3) may be expressed by:

$$
\begin{aligned}
& W_{c}(\alpha)=\frac{1}{4 \mu_{0}} L_{s}\left(R_{o}^{2}-R_{i}^{2}\right) \\
& {\left[\sum_{n=0}^{\infty} P_{n N_{L}} B_{n N_{L}} \int_{0}^{2 \pi} \cos n N_{L} \theta \cos n N_{L}(\theta+\alpha) d \theta\right]} \\
& =\frac{1}{4 \mu_{0}} L_{s}\left(R_{o}^{2}-R_{i}^{2}\right) \cdot 2 \pi \cdot \sum_{n=0}^{\infty} P_{n N_{L}} B_{n N_{L}} \cos n N_{L} \alpha
\end{aligned}
$$

where $N_{L}$ is the least common multiple (LCM) of the number of slots and pair-poles. Finally the equation (2) may be expressed by:

$$
\begin{aligned}
\tau_{c o g} & =-\frac{\partial W_{c}}{\partial \alpha} \\
& =\frac{\pi L_{s}}{2 \mu_{0}}\left(R_{o}^{2}-R_{i}^{2}\right) \cdot \sum_{n=0}^{\infty} P_{n N_{L}} B_{n N_{L}} \sin n N_{L} \alpha
\end{aligned}
$$

In this way, the magnetic flux and stored energy vary with different rotor angle positions. In the above equations, the magnetic flux variation results in a variation in the cogging torque. Achieving a reduction in the cogging torque by considering the ratio of the pole arc to the pole pitch is effectively applicable for PM brushless machines [2]. The cogging torque period is also defined by the number of poles and slots as shown in the equation (7). The cogging torque seen in a PM machine can be modeled by the sum of all produced fundamental torques because of the interaction between each magnet and the edges of the slot opening [9]. In a slot-pitch rotation, the number of the cogging torque periods, $N_{L}$, is an important indicator that they provide information about the spatial displacement of the fundamental the cogging torque

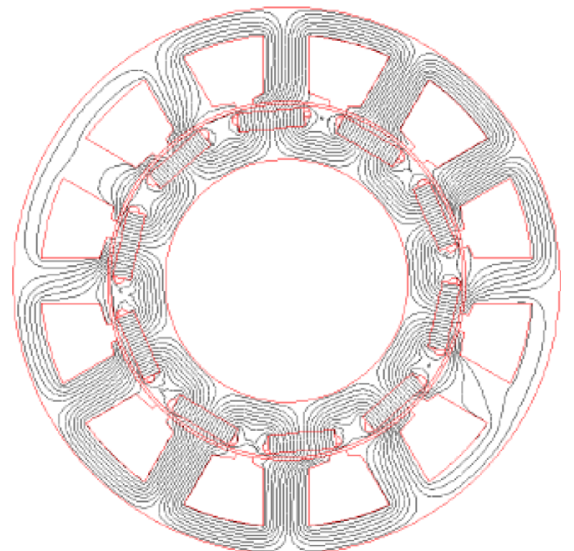

Fig. 1. (Color online) Flux plots in the PM machine under noload current conditions.

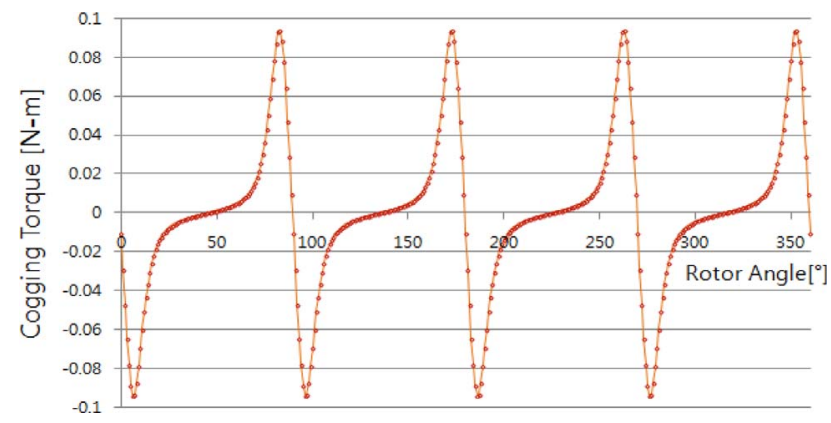

Fig. 2. (Color online) Cogging torque waveform.

waveforms.

The design factors for the magnetic flux variation that affect the amplitude and the frequency of the cogging torque are the slot/pole combinations, magnetic pole-arc, the slot-opening width, and the uniformed/non-uniformed teeth of the machine. Therefore, while selecting the machine topology, it is important to choose a suitable $N_{s}$ and $N_{p}$ relation in order to minimize the cogging torque. However, for a further reduction of the cogging torque in applications where the requirements for these parameters are rigorous, different methods have been developed and used in the past.

\subsection{Investigation of the Cogging Torque Affecting Factors}

Next, we investigate some of the factors that affect the cogging torque in order to reduce the cogging torque in a given stator-lamination configuration and magnet-mounting configuration in the rotor.

\subsubsection{Slot Opening}

The slot opening significantly affects the cogging torque. To show the differences in the variation of the cogging 


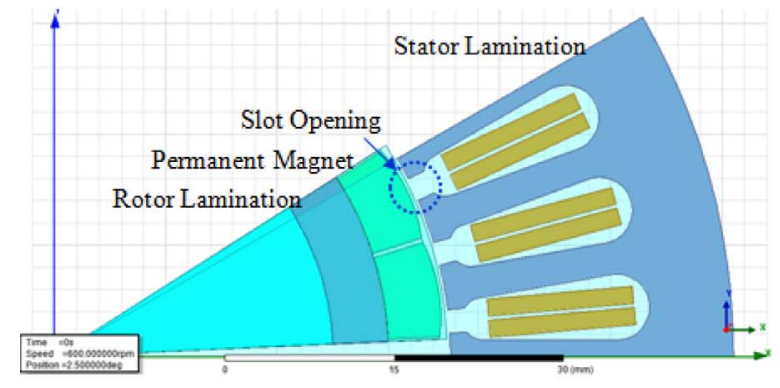

(a)

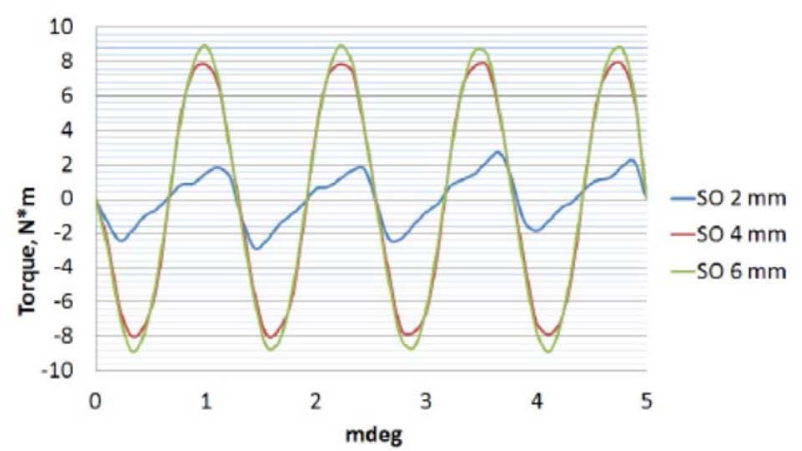

(b)

Fig. 3. (Color online) Cogging toque with different slot openings of the stator: (a) FEA model, (b) comparison of the cogging torque.

torque, we analyzed and compared the three different slot openings with widths of 2, 4, $6 \mathrm{~mm}$.

From Fig. 3, we see that the cogging torque has the minimum amplitude when the slot opening is $2 \mathrm{~mm}$, and is a maximum when the slot opening is $6 \mathrm{~mm}$. We can conclude that to reduce the torque ripple, we should use the smallest possible slot-opening. From a manufacturing point of view, it is not convenient to install a winding through a small slot opening that is too small. In our case, the slot opening must be at least $2 \mathrm{~mm}$.

\subsubsection{Slot Skewing}

Generally, the cogging torque of the PM generator can be eliminated only by slot skewing. On the other hand, the slot skewing makes the stator construction more complicated. The stator slot skewing decreases the effective cross section of a slot, increases the length of the conductors, and decreases the electromotive force of the machine $[1,2]$. The influence of different rates of slot skewing to the level of the cogging torque of the PM generator was compared in Fig. 4 which shows the cogging torques obtained at each skews angle ratio of 0 ,
$0.12,0.5,0.75$ slot pitch within one the cogging torque periods. In our case, the cogging torque can be eliminated when the skew angle is given by:

$$
\alpha_{S K E W}=\frac{N_{s}}{\operatorname{LCM}\left(N_{s}, N_{p}\right)}
$$

It can be seen from the graph that the skew of 0.75 slot pitches can contribute to an $80 \%$ reduction from no skew in the cogging torque. The slot pitch is defined by the ratio of circumferential skew to one slot pitch between two adjacent slots.

\subsubsection{Mounting of the Magnet}

When designing the PM machine, the effect of the

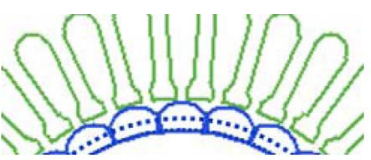

(a)

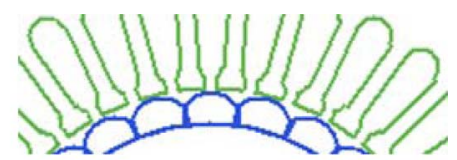

(b)
Fig. 5. (Color online) Generator construction with: (a) embedded magnet, (b) surface magnet.

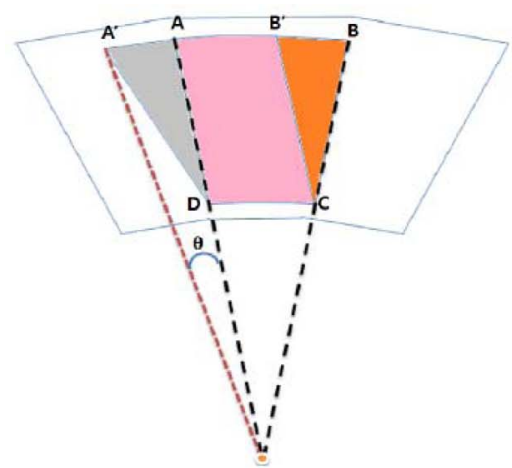

(a)

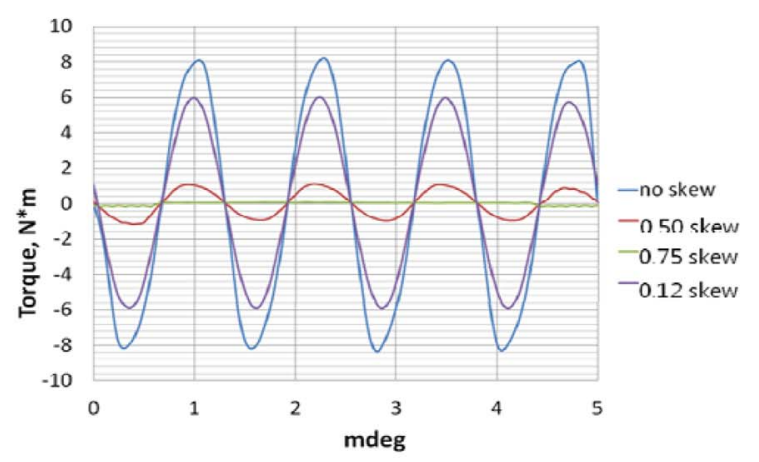

(b)

Fig. 4. (Color online) Cogging torque as a function of different stator slot skews: (a) Skews of stator slot pitch, (b) Comparison of the cogging torque. 


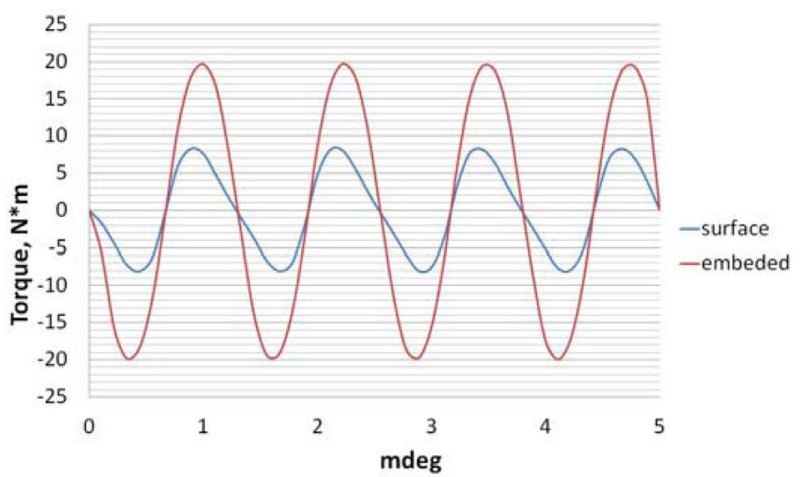

Fig. 6. (Color online) Cogging torque as a function of the rotor magnet mounting method.

mounting of the magnets should be considered. We investigated and compared different surface and embedded magnet designs. The compared designs are shown in Fig. 5. Fig. 6 shows the difference in the cogging torque for the embedded and surface-mounted magnet designs. The embedded design has a higher torque ripple because of the interaction between the stator and rotor teeth. On the other hand, machines with surface-mounted magnets have a significantly reduced electromotive force.

\subsubsection{Magnet Shape}

The different PM shapes shown in Fig. 7 which affects the torque ripple significantly. Fig. 8 shows that the cogging torque can be reduced by increasing the angle of the magnet pole arc. The magnet shape 1 has a maximum arc-pole angle, while the magnet shape 3 has the minimum angle.

\subsubsection{Combinations of Different Number of Slots/Pole}

We investigated the effects of the slots and pole combinations based on three phase generators of $1 \mathrm{~kW}$ at $300 \mathrm{rpm}$ that are used for wind energy conversion. From a machine winding perspective, the multi-pole magnetic structure imply a fractional three-phase winding; the influence of the number of slots/poles/phases $(q)$ is more

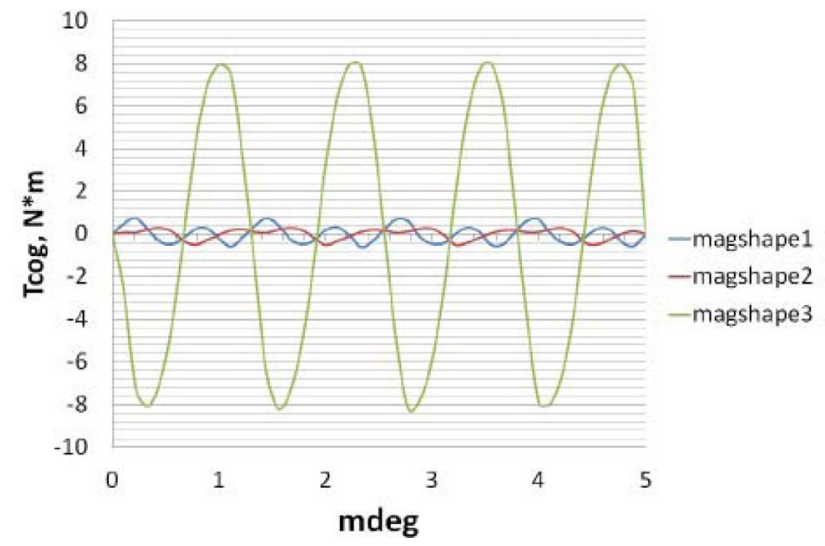

Fig. 8. (Color online) Cogging torque at different angles of the magnet poles.

concerned, and the investigated number of slots per pole per phase is $36 / 24 / 3(q=0.5), 36 / 26 / 3(q=0.462)$, and $72 / 24 / 3(q=1.0)$. The tooth concentrated windings shown in Fig. 9 which has a coil pitch equal to one. Therefore, the manufacture of such three-phase windings requires a value of $q$ that is equal to or less than $1 / 2$; otherwise, the winding pitch factor would be too low. To verify this assertion, we can analyze a simple three-phase winding with $N_{s}=6$ slots and two poles $(q=1$, "concentrated winding"). If the coil pitch(y) is $y=3$, the distribution winding will have the fundamental distribution winding factor $k_{w 1}=1$. If $\mathrm{y}=2$, It will result in $k_{w 1}=0.866$. If the winding is "tooth concentrated," $y=1$, and the winding factor becomes $k_{w 1}=0.5$. This results in double the number of turns/phase for the same machine performances. In the limit case of $q=1 / 2$ (number of slots equal to 1.5 times the number of poles), there is no "distribution" of the coils, and the fundamental winding factor will be $k_{w 1}=0.866$, as it is the pitch factor.

Three winding configurations with $N_{s} / N_{p}$ equal to $36 / 24$ and 36/26 have been designed in double layers. Fig. 9 shows the 36-slots, 24-poles winding arrangement with all the phase coils connected in series (for this configuration, there is also the option of having two parallel

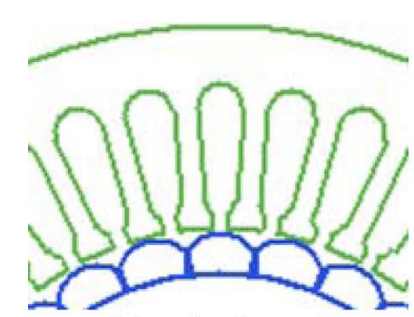

(a) pole shape 1

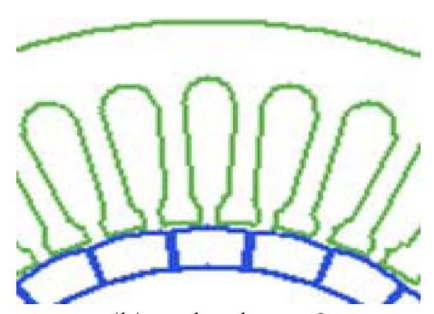

(b) pole shape 2

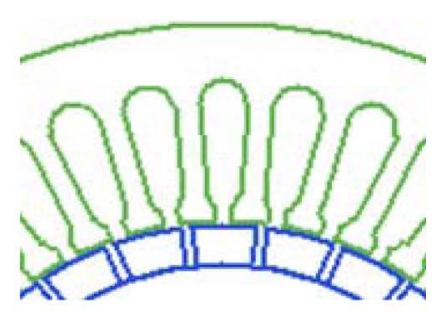

(c) pole shape 3

Fig. 7. (Color online) Different angles of the magnet poles: (a) large pole arc (shape 1), (b) small pole arc (shape 2), (c) flat pole (shape 3). 
Table 1. Simulation results of the cogging torque analysis.

\begin{tabular}{cccccc}
\hline \hline $\begin{array}{c}\text { Rated } \\
\begin{array}{c}\text { Power/speed } \\
(\mathrm{kW} / \mathrm{rpm})\end{array}\end{array}$ & $N_{s} / N_{p}$ & $\mathrm{q}$ & $\begin{array}{c}\text { Rated } \\
\text { Torque } \\
(\mathrm{N}-\mathrm{m})\end{array}$ & $\begin{array}{c}\text { Max. } \\
\text { cogging } \\
\text { torque }(\mathrm{N}-\mathrm{m})\end{array}$ & $\begin{array}{c}\text { Cogging } \\
\text { torque } \\
(\%)\end{array}$ \\
\hline $5 / 300$ & $72 / 24$ & 1.0 & 198.74 & 16.36 & 8.23 \\
$5 / 300$ & $36 / 24$ & 0.5 & 198.74 & 10.58 & 5.32 \\
$5 / 300$ & $36 / 26$ & 0.462 & 198.74 & 3.43 & 1.72 \\
\hline
\end{tabular}

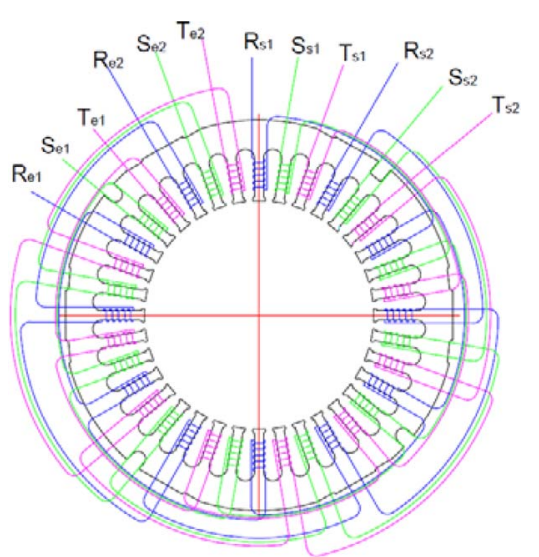

Fig. 9. (Color online) Tooth concentrated windings.

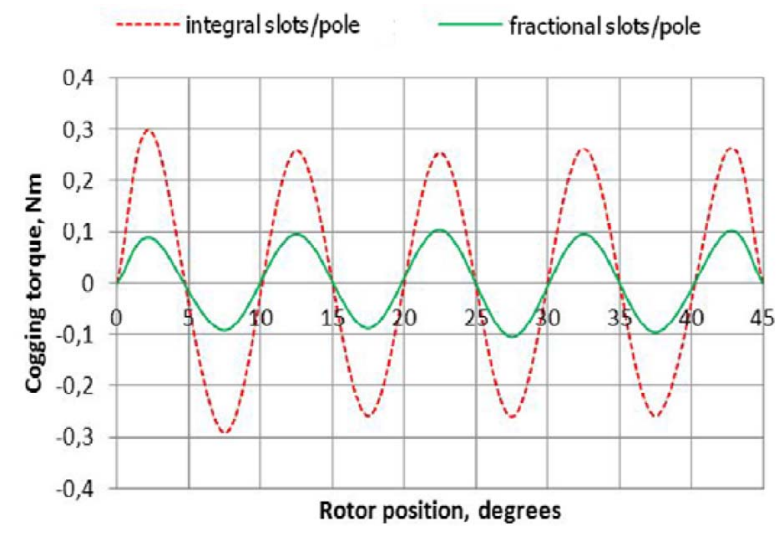

Fig. 10. (Color online) Cogging torque with varying numbers of slot per pole.

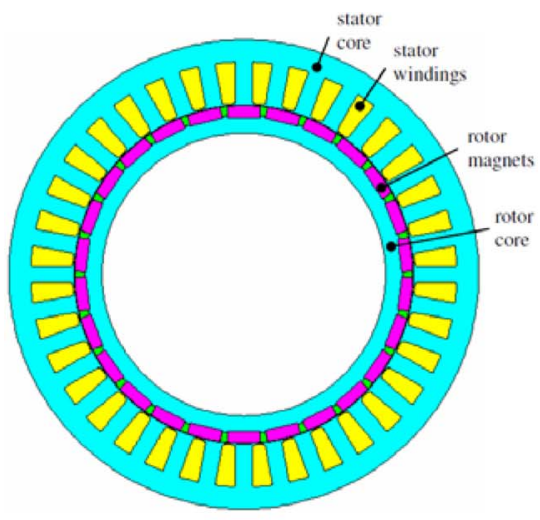

(a)

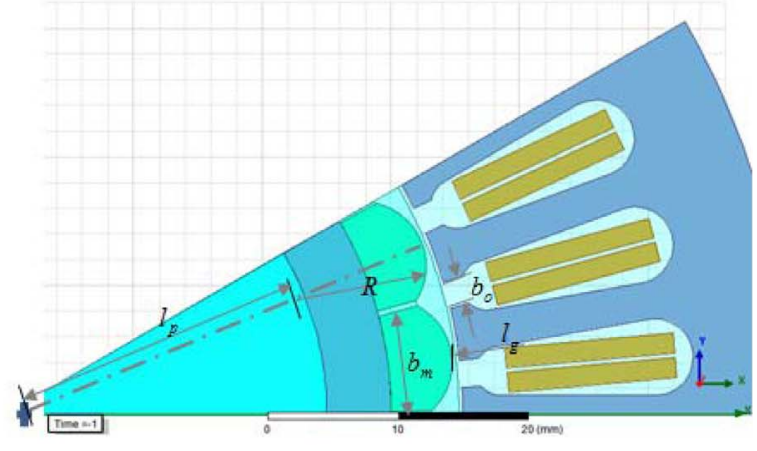

(b)

Fig. 11. (Color online) Candidate model: (a) geometric layout, (b) optimal design parameters.

\begin{tabular}{|c|c|c|c|}
\hline Items & Parameters & Unit & Values \\
\hline \multirow{10}{*}{ Stator } & Average air-gap & $\mathrm{mm}$ & 0.6 \\
\hline & No. of slots & ea & 36 \\
\hline & No. of windings & ea & 18 \\
\hline & Outer diameter & $\mathrm{mm}$ & 225 \\
\hline & Inner diameter & $\mathrm{mm}$ & 140 \\
\hline & Stack length & $\mathrm{mm}$ & 30 \\
\hline & Core material & - & S60 \\
\hline & Coils in each winding & turns & 92 \\
\hline & Stator tooth width & $\mathrm{mm}$ & 4.2 \\
\hline & Stator slot opening width & $\mathrm{mm}$ & 2 \\
\hline \multirow{6}{*}{ Rotor } & No. of magnets & ea & 24 \\
\hline & Magnet material & - & Nd-Fe 35 \\
\hline & Outer diameter & $\mathrm{mm}$ & 138.8 \\
\hline & Inner diameter & $\mathrm{mm}$ & 90 \\
\hline & Magnet mounting type & - & Surface \\
\hline & Speed range & $\mathrm{rpm}$ & 200 to 600 \\
\hline
\end{tabular}

\subsection{FE Analysis Model}

The FEA method is used to compute the machine behavior in order to predict the performance of the potential

Table 2. Design parameters for candidate analysis only the two highest sub-harmonics. It is interesting to wave does not have constant magnitude under different poles. With respect to the cogging torque, the simulation data for the machine under investigation are shown in Table 1.

\section{Cogging Torque Reduction Analysis and Results}

paths). The armature reaction $\mathrm{mmf}$ (the mmf produced only by the no-load current in the phase windings) is computed taking into account the fundamental wave and note that the main harmonic is modulated by the subarmonics and the magnitude of the resulting rotating (1) 
Table 3. Optimal design variables for analysis model.

\begin{tabular}{lccccccc}
\hline \hline \multirow{2}{*}{ Factors } & \multirow{2}{*}{ Units } & \multicolumn{6}{c}{ Steps (Lower and upper bound) } \\
\cline { 3 - 8 } & & 1 & 2 & 3 & 4 & $X_{L}$ & $X_{U}$ \\
\hline Magnet embrace $(R)$ & $\mathrm{mm}$ & 33.7 & 33.2 & 32.5 & 31.5 & 20 & 40 \\
Slot opening $\left(b_{o}\right)$ & $\mathrm{mm}$ & 1.6 & 1.8 & 2.0 & 3.0 & 1.5 & 3.0 \\
Skew angle $\left(\alpha_{S K}\right)$ & (ratio) & 0.75 & 0.78 & 0.80 & 0.5 & 0.7 & 1.0 \\
\hline
\end{tabular}

design for the application of combined methods. A nonlinear field analysis is carried out for the magnetic flux density calculation in every nodes singular of the candidate model. On the other hand, the commercially available Maxwell 2D software incorporates tools that can achieve this analysis [17, 18]. Given the symmetry of a PM machine, every half of the machine relative to the center plane, mirrors the other half in the radial direction. Thus, it is possible to model only one-sixth of the machine comprising the rotor, the air-gap clearance, and the stator, as shown in Fig. 11.

For the FE and experimental analysis, a 24 poles, 36 slots PM generator was used as the machine design parameters, and this is summarized in Table 2. We choose a configuration with 24 poles, 36 slots with 18 windings because it offers better magnet utilization with a smaller rotor diameter. Based on our analytical calculations, a generator was sized and designed to develop a $1-\mathrm{kW}$ supply at the rated speed of $300 \mathrm{rpm}$. To reduce the cost of the prototype, we used off-the-shelf magnets.

\subsection{Combined Methods and Design Optimization}

This paper examined the combination of methods that the most significant design factors affecting the cogging torques of the above methods are chosen as the slot opening width of stator $\left(w_{\text {SLOT }}\right)$, the skew angle of stator $\left(\alpha_{S K}\right)$, and the embrace angle of pole arc $\left(\alpha_{M}\right)$. The design factors of a PM generator, the dimensional equations for the machine are related to the choice of the objective functions [16]. Here, in the reduction of the cogging torque of the proposed generator, the main goal is to minimize the average value and variance of the cogging torque while ensuring the maximum possible normal torque. Objective function in the design optimization with the performance constraints was defined by Eq. (9). To achieve this goal of minimizing the cogging torque, the design variables are carefully chosen by Eq. (13).

$$
\begin{aligned}
& \text { Minimize } f(X)=\frac{1}{n} \sum_{n=0}^{n}\left[h_{i}(X)+w_{p} P_{i}(X)\right]^{2} \\
& \text { where, } h(X)=T_{\text {cog_max }} \\
& \qquad P_{i}(X)=\sum_{j=1}^{2}\left\{\max \left[0, g_{j}(X)\right]^{2}\right\} \\
& \text { subject to }\left\{\begin{array}{c}
g_{1}(X)=150-T_{\text {avg }} \leq 0 \\
g_{2}(X)=\frac{T_{\max }-T_{\min }}{T_{\text {avg }}} \times 100-20.0 \leq 0 \\
X_{L} \leq X \leq X_{U}
\end{array}\right. \\
& X=\left(w_{S L O T}, \alpha_{S K}, \alpha_{M}\right)
\end{aligned}
$$

where $f(X)$ is the objective function, $h(X)$ is the maximum value of the cogging torque, $P(X)$ is the penalty functions of $g_{1}(X)$ and $g_{2}(X), w_{p}$ is the weighting factor, $g_{1}$ is the constraint function of average normal torque, $g_{2}$ is the constraint function of torque ripple, $X$ is the optimal design variables which are chosen as $w_{S L O T}$ is the slot opening width of stator, $\alpha_{S K}$ is the skew angle of stator, $\alpha_{M}$ is the embrace angle of pole arc, and $X_{L}, X_{U}$ are lower and upper bounds of each variables, respectively, as shown in Table 3.

The optimization algorithm of enhanced Taguchi method with sequential quadratic programming (SQP iterative solver) $[16,17]$ was used for this solution. Table 4 shows the optimal design results of design variables and expected performance of object functions. The use of parametrization techniques can deal with each dimension of the machine's geometry as a variable, allowing the faster determination of the FE models, enabling us to modify and adjust the parameters, and for each calculation process, to determine the effects on the cogging torque of the modified constructive parameter, as described in above. We carried out an FEA time-transient simulation using

\begin{tabular}{|c|c|c|c|c|c|}
\hline Design Variables & Units & Optimal Values & Object Functions & Units & $\begin{array}{c}\text { Expected } \\
\text { Performance }\end{array}$ \\
\hline Magnet embrace $(R)$ & $\mathrm{mm}$ & 33.7 & Cogging Torque $\left(T_{\text {cog_max }}\right)$ & $\mathrm{Nm}$ & 0.165 \\
\hline Slot opening $\left(b_{o}\right)$ & $\mathrm{mm}$ & 1.6 & Torque Average $\left(T_{a v g}\right)$ & $\mathrm{Nm}$ & 151 \\
\hline Skew angle $\left(\alpha_{S K}\right)$ & (ratio) & 0.75 & Torque Ripples $\left(\mathrm{T}_{\text {ripple }}\right)$ & $\%$ & 2.08 \\
\hline
\end{tabular}
the available design and simulation tools $[18,19]$. The FE method was used for the computation of the candidate machine behavior. A nonlinear field analysis was carried

Table 4. Performance indication for optimal design results. 


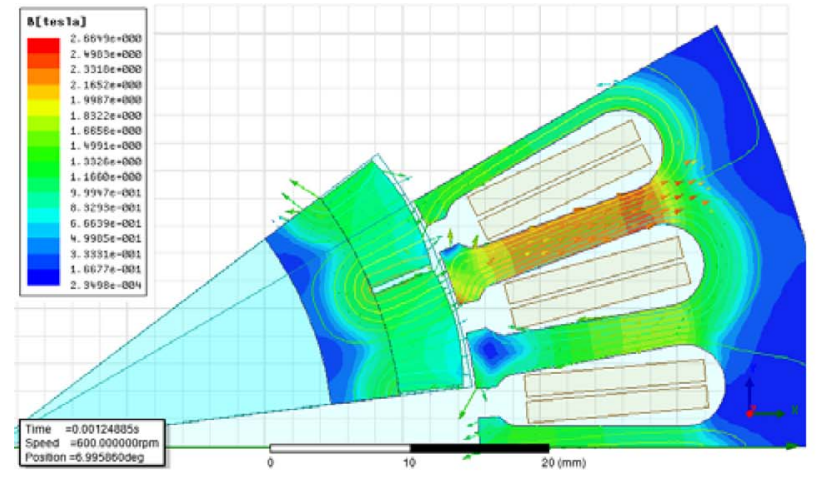

(a)

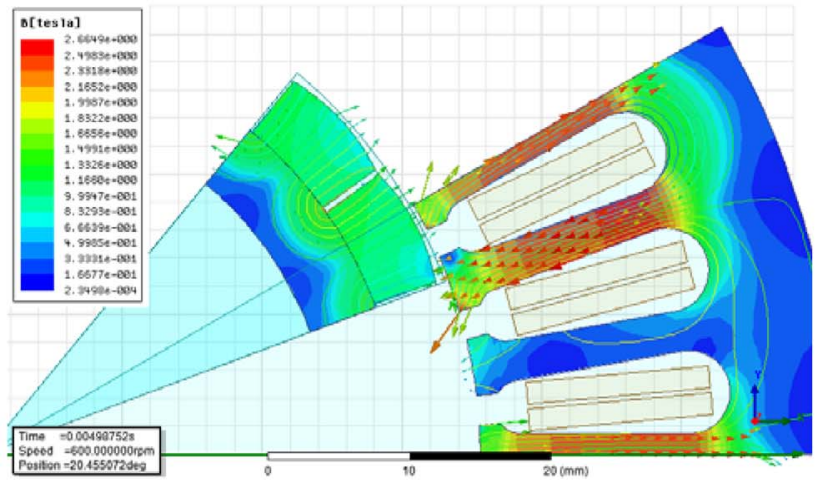

(c)

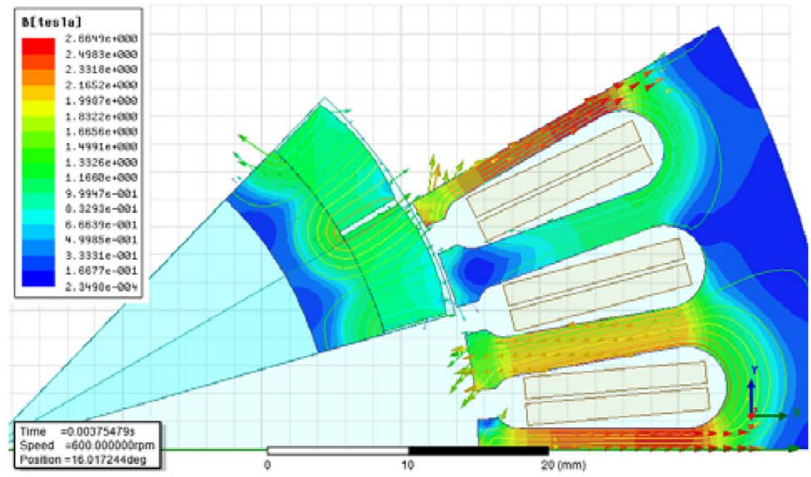

(b)

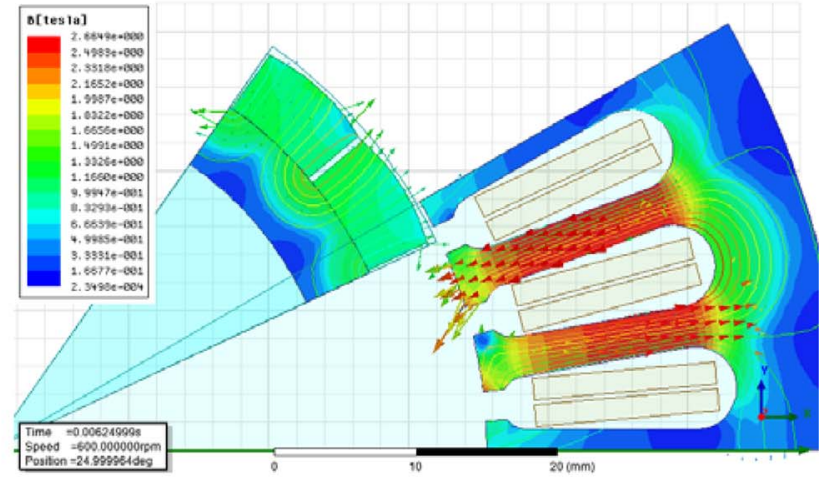

(d)

Fig. 12. (Color online) Flux line and flux density analysis at different rotor angle position: (a) rotor angle $0^{\circ}$, (b) rotor angle $10^{\circ}$, (c) rotor angle $18^{\circ},(\mathrm{d})$ rotor angle $25^{\circ}$.

out for the magnetic flux density calculation in each singular node of the model. We used a two-dimensional FE model in our analysis. The cogging torque was calculated by simulating the machine behavior in no-load conditions (without current in the stator windings) for different rotor positions. For each rotor position, the model mesh is automatically recalculated.

\subsection{FE Analysis Results}

We examined this combination of methods using the FE method and a set of prototyped generators to provide experimental results. While the use of a fractional number of slots per pole reduces the amplitude of the cogging torque, it also increases the fundamental order (deformation of the waveform of the magnetic flux density in the air gap of the machine). This is because the stator slots are located at different relative circumferential positions with respect to the edges of the magnets. In general, the higher the least common multiple between the number of the poles and the number of stator slots, the lower will be the cogging torque. Because of the slight eccentricity on the rotor surface caused by the manufacturing process, a component of the cogging torque had one period per

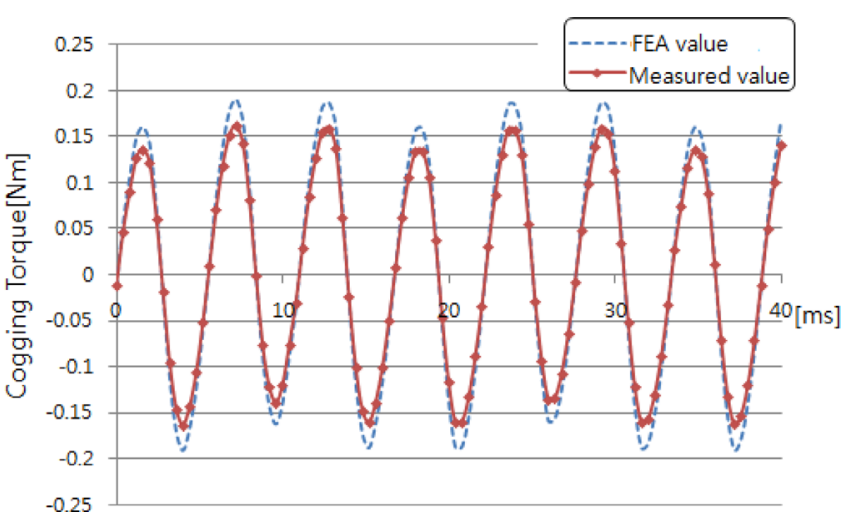

Fig. 13. (Color online) Cogging torque of FEA simulation and measured values at speed of $300 \mathrm{rpm}$.

stator tooth. Because it is a relatively small machine, the tolerances required by the design were too high for the available machine shop. Fig. 12 shows the magnetic flux density distribution of the candidate machine at different rotor angle positions. As a function of the angle rotation of the rotor, the cogging torque value of the machine was also provided in Fig. 13, and the FEA and measured values were compared and discussed. It can be seen from Fig. 13 that the maximum peak-to-peak value of the 


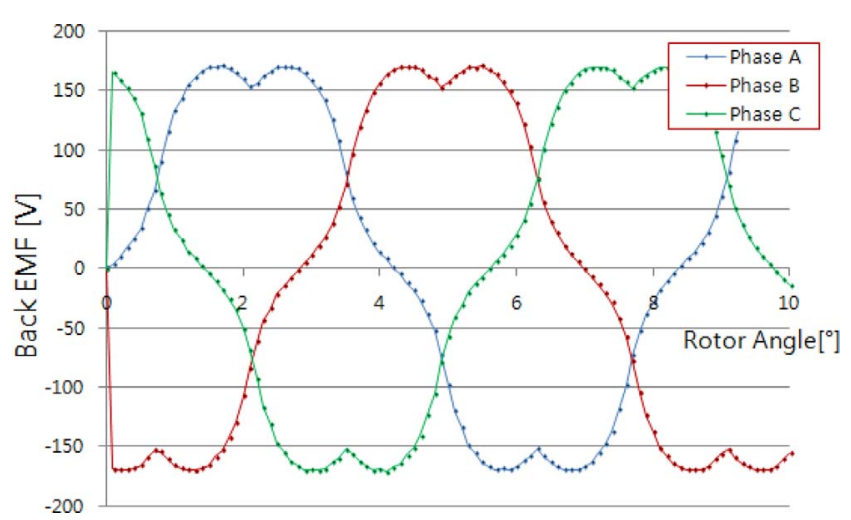

Fig. 14. (Color online) No-load Back EMF waveform.

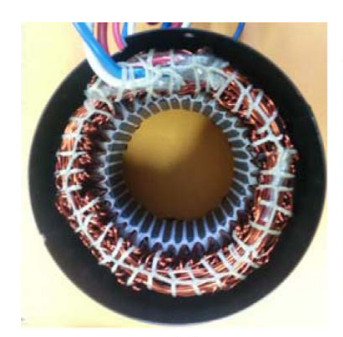

(a)

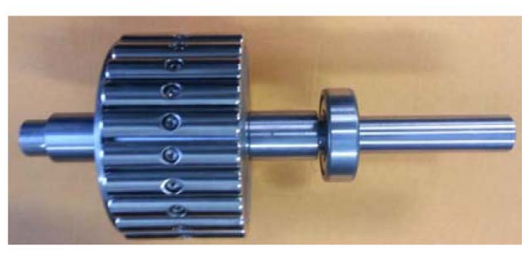

(b)
Fig. 15. (Color online) Manufactured PM generator for experimental analysis: (a) Stator (b) Rotor.

cogging torque is about $0.3 \mathrm{~N}-\mathrm{m}$, whereas the measured value at $300 \mathrm{rpm}$ is about $0.28 \mathrm{~N}-\mathrm{m}$. Moreover, the maximum the cogging torque value at $50 \mathrm{rpm}$ was measured to be about $0.03 \mathrm{~N}-\mathrm{m}$. In addition, the fluctuations that were due to the faults of the different small-angle placements of the PMs were observed between some the cogging torque values. The measured back EMF of candidate machine at no-load condition is shown in Fig. 14.

In order to validate the numerical simulation results we used an experimental facility consisting of the studied PM generator as shown in Fig. 15 which is rotated with a slow velocity and a specialized torque transducer with automatic data recording system. The measurement data obtained were numerically processed in order to eliminate the friction torque influence on the cogging torque results. A good agreement can be noticed between the peak-topeak values of FEA and the experimental results presented in Fig. 13.

\section{Conclusion}

In this paper, we examined the combination of methods that the most significant design factors affecting the cogging torques of the above methods are chosen as the slot opening width of stator $\left(w_{\text {SLOT }}\right)$, the skew angle of stator $\left(\alpha_{S K}\right)$, the embrace angle of pole arc $\left(\alpha_{M}\right)$ for the reduction of the cogging torque of a PM generator for small wind-power turbines. The torque values calculated using these methods were found to be much smaller than those calculated on the conventional machine, justifying the use of these methods as an effective method for reducing the cogging torque in these types of machines. The performance of various constructive parameters as a method to reduce the cogging torque is much higher for machines with an integer number of slots per pole, where the evolution of the cogging torque with the studied parameter is more predictable. The FE analysis gave results that are in good agreement with the design optimization, with respect to the air-gap flux density, the induced phase voltage, the output power, and the cogging torque. The technique employed to reduce the cogging torque for a PM generator is suitable for use in a small wind turbine. These machines can be compact and have high power density, and they are axially short with larger diameters. This makes them suitable for wind turbines. At First, because of the interaction between the magnets and the variable permeance of the stator, the corresponding torque ripple component, i.e., the cogging torque may be very important. Considering the wind turbine applications, if the rated power occurs at a rated wind speed that is on average $10 \mathrm{~m} / \mathrm{s}$, the wind turbine has to be started (at noload) at a wind speed of $2.5-3 \mathrm{~m} / \mathrm{s}$. Considering that the delivered power varies with the wind speed at the power of $1 \mathrm{~kW}$, in an optimized design, the cogging torque should be less than $1.5-2.5 \%$ from the rated torque. Secondly, because of the large number of poles, the number of fractional slots per pole configurations has to be used. This will also minimize the cogging torque. This significantly improves the turbine performance at low start-up speeds, while maintaining high power density. This technique can reduce manufacturing confusion in the $\mathrm{N} / \mathrm{S}$ pole placement and allow a simple magnet shape for lower cost manufacturing.

\section{Acknowledgement}

This study was supported by a research grant from Honam University, 2013.

\section{References}

[1] D. Hanselman, Brushless Permanent-Magnet Motor Design, New York, McGraw-Hill, 1994.

[2] T. J. E. Miller, Speed's Electric Motors: An outline of some of the theory in the speed software for electric 
machine design with problems and solutions, University of Glasgow (2008) pp. 475.

[3] D. W. Chung and Y. M. You, J. Magn. 19, 273 (2014).

[4] G. C. Lee and T. U. Jung, J. Electr. Eng. Technol. 8, 1590 (2013).

[5] Z. Q. Zhu and D. Howe, IEEE Trans. Energy Convers. 15, 407 (2000).

[6] Z. Q. Zhu, S. Ruangsinchaiwanich, N. Schofield, and D. Howe, IEEE Trans. Magn. 39, 3238 (2003).

[7] L. Dosiek and P. Pillay, IEEE Trans. Ind. Appl. 43, 1656 (2007).

[8] E. Muljadi and J. Green, Cogging torque reduction in a permanent magnet wind turbine generator, in Proc. of the 21st Am. Soc. of Mech. Engineers Wind Energy Symp., (2002) pp. 1-8.

[9] J. A. Guëmes, P. M. Garcia, and A. M. Iraolagoitia, Influence of slot opening width and rotor pole radius on the torque of PMSM, ICREPQ'09 (2009) pp. 1-5.

[10] N. Levin1, S. Orlova1, V. Pugachov1, B. Ose-Zala1, and E. Jakobsons, Methods to reduce the cogging torque in permanent magnet synchronous machines, ISSN 13921215, 19, 23 (2013).

[11] R. Islam, I. Husain, A. Fardoun, and K. McLaughlin, IEEE Trans. Ind. Appl. 45, 152 (2009).

[12] K. Abbaszadeh, F. R. Alam, and S. A. Saied, Energy Conver. and Manag. 52, 3075 (2011).

[13] P. Lampola, PhD Thesis, Acta Politechnica Scandinavica, Electrical Engineering Series 101, Espoo, 23 (2000).

[14] L. Zhu, S. Z. Jiang, Z. Q. Zhu, and C. C. Chan, IEEE Trans. Magn. 45, 2023 (2009).

[15] C. U. Lee, D. W Kim, and D. H Kim, J. Korean Magn. Soc. 24, 160 (2014).

[16] S. Lee, Master Thesis, KAIST, Korea (1998).

[17] J. S. Arora, Introduction to Optimal Design, Elseview, New York (2004).

[18] RM and Maxwell 3D Field Simulator User's Reference, ANSYS (Ansoft Corp.) Pittsburgh, PA (2008).

[19] K. C. Kim and S. K. Lee, Maxwell 2D/3D Training Manual for User Applications, Ansoft Co. User Group, Seoul, Korea, 1234 (2010). 